\title{
Optimal money growth in a limited participation model with heterogeneous agents
}

\author{
Erdem Başç ${ }^{1}$, Ismail Saglam ${ }^{2}$ \\ 1 The Central Bank of Republic of Turkey, Ankara 06100, Turkey \\ (e-mail: Erdem.Basci@tcmb.gov.tr) \\ 2 Department of Economics, Bog̃aziçi University, Bebek, Istanbul 34342, Turkey and \\ Department of Economics, Bilkent University, Bilkent, Ankara 06800, Turkey \\ (e-mail: saglamis@boun.edu.tr)
}

Received: 16 August 2003 / Accepted: 22 March 2005

\begin{abstract}
This paper studies optimal money growth in a cash-in-advance production economy with heterogeneity in patience levels and know-how. We show that the rate of deflation suggested by the Friedman rule is limited by the subjective discount rate of the most patient agent in the economy. The output distortion due to cash-in-advance constraints on firms can completely be eliminated by means of the Friedman rule if and only if firms are run by the most patient agents.
\end{abstract}

JEL classification: D52, D90, E21, E41, E52

Key words: Cash-in-advance, limited participation, inflation, Friedman rule

\section{Introduction}

The central bankers of the world are quite reluctant to follow a deflationary policy. The Federal Reserve System of US, the Monetary Policy Commitee of UK, and

Parts of this paper were completed while the first and second authors were visiting the University of York and Princeton University respectively. We are thankful for the hospitality of these institutions. The second author also acknowledges the hospitality and support of Bilkent University that he is currently visiting, the support from the Turkish Academy of Sciences in the framework of the 'Distinguished Young Scientist Award Program' (TUBA-GEBIP/2004), the grant awarded by the Scientific and Technical Research Council of Turkey (TUBITAK) under the NATO Science Fellowship Program as well as the support from the Center for Economic Design of Bogaziçi University. This paper was presented in the ERC/METU Second International Conference on Economics, Ankara, September 1998, and at seminars in Bilkent, Bog̃aziçi and Ohio State Universities. We thank, in particular, Emre Alper, Sumru Altug̃ , Huw Dixon, Tatsuro Ichiishi, Ivan Pastine, Murat Sertel and Alan Sutherland for useful comments. We also thank two anonymous referees for comments and suggestions. The views expressed in this paper are those of the authors and do not necessarily reflect that of the Central Bank of Republic of Turkey. 
the European Central Bank all target a non-negative but small inflation rate. After the Great Depression and the more recent Japanese experience with deflation, widespread belief among policy-makers is that deflations typically come together with a collapse of economic activity. The theoretical reasons, however, are not yet well understood.

Leaving aside the literature on seignorage maximization, monetary theory suggests that a small steady state deflation consistent with zero nominal interest rate in equilibrium should turn out to be socially optimal. This rule has first been suggested by Friedman (1969) and has been justified in various homogeneous agent models later on.

In this paper we show that heterogeneity in preferences matters with regard to what monetary policy can achieve. The underlying reason is that under heterogeneous rates of time preference, the extent of a feasible deflation is restricted by the subjective discount rate of the most patient agent in the economy. Higher rates of deflation results in either money hoarding by consumers or financial losses by firms and hence breaks down the existence of a stationary monetary equilibrium. This obstacle alone restricts the policymaker's ability to reduce the monetary output distortion by means of a deflationary policy.

The argument that the optimal rate of money growth is a deflationary one (Friedman 1969) has been verified in various forms of cash-in-advance models with representative agents. The Friedman argument is that money has the role of reducing a trading friction in the economy. Since an inflationary monetary policy leads agents to economize on real money balances, it results in a sub-optimal equilibrium. In Cooley and Hansen (1989), for example, money carried over from one period to the next consists of nominal wage earnings, which are subject to the inflation tax, so that the aggregate labor supply decision is adversely affected by inflation. Woodford (1994), on the other hand, studies the issue in the Lucas and Stokey (1987) setup where both cash and credit goods are consumed by the representative agent. In this case inflation leads to a reduction in the quantity of cash goods consumed. In either case, a deflation in line with the representative agent's rate of time preference is sufficient to eliminate the distortion caused by the presence of finance constraints. ${ }^{1}$

Yet another interesting class of cash-in-advance models are those which involve limited participation in factor markets by firms. It is a natural assumption for many industries that production expenses are incurred before sales revenues are collectible. Implications of such constraints in production and/or investment expenses on equilibrium were studied by Stockman (1981), Grossman and Weiss (1983) and Rotemberg (1984). Their applications to the business cycles literature have also been considerably successful (Fuerst 1992; Christiano et al. 1997, 1998). In this class of models money, which is demanded by firms as working capital, is subject to inflation tax. In stationary equilibria of limited participation models, holders of money are compensated at the expense of a reduction in real wages, in comparison to what would prevail in an Arrow-Debreu economy. This real wage

1 Bewley (1980) is the first rigorous treatment of the issue of optimal money growth. Woodford (1990) provides a survey of this and later work on the same problem. 
distortion can be completely eliminated by a deflationary monetary policy if all the agents have the same rate of time preference (Başçı and Saglam 1999). ${ }^{2}$

In the present paper, we allow for heterogeneity in both technologies and time preferences of the agents, in the context of a limited participation model. The main trading friction is a moral hazard problem, which necessitates all exchange to be quid pro quo. This rules out borrowing of any kind as well as any "sales-in advance" of to-be-produced goods. Presence of money reduces this trading friction in the context of a limited participation economy. Firms have to pay for the factors of production first, and only after they produce their goods can they collect their sales revenues. In equilibrium, it turns out that all the money in the economy is held by the firm types who own technologies superior than those of worker types. In this mode of hundred per cent self financing, the working capital of a firm type is subject to inflation tax. Higher inflation rates lower firms' real money demands (by cutting their net supply of goods), and hence bid up the equilibrium price level, so that the real wage is driven below the marginal product of labor. This real wage distortion affects the labor supply in each period and hence reduces equilibrium output below its Arrow-Debreu level. In the representative agent framework of Fuerst (1992), for example, a deflation, that equates the real rate of return on money to the subjective rate of time preference of the representative agent, is sufficient to eliminate the monetary distortion completely. The same result obtains under heterogeneous technologies but homogeneous rates of time preference as shown in Başçı and Saglam (1999).

If, however, the rates of time preference are different, then there are two potential distortions in the monetary economy. One is the aforementioned real wage-real output distortion. The other is a distortion on consumption paths due to the liquidity constraints that exclude the possibility of borrowing by the relatively impatient agent types. In an Arrow-Debreu economy, the equilibrium allocation would consist of one where the consumption of the patient and impatient types are increasing and decreasing over time, respectively. In our limited participation economy, however, due to borrowing constraints consumption levels are constant over time for both agent types in a stationary equilibrium. While this second type of consumption distortion cannot be eliminated by deflationary policies alone, the real wage and output distortion can be reduced via a contraction in money supply.

The paper is organized as follows. Section 2 introduces the model. Section 3 characterizes the set of stationary monetary competitive equilibria. Section 4 analyzes equilibrium in cases where it is unique. Section 5 derives the second best optimal monetary policy. The robustness of the results under differences in the timing of the lump-sum monetary transfers and taxes is discussed in Sect. 6. The paper concludes with the remarks in Sect. 7.

\footnotetext{
2 The empirical studies in the literature do not agree on the relationship between money and output growth. Kormendi and Meguire (1985) finds in a cross-country analysis that the average rate of growth of the money supply and the standard deviation of money supply shocks are both negatively correlated with real output growth. However, another cross country study by Levine and Revelt (1992) finds no robust correlation between monetary indicators and real GDP growth. A positive correlation is recently reported in Barth and Ramey (2002), which shows that following a monetary contraction, many industries in US exhibit periods of falling output and rising price-wage ratios.
} 


\section{The model}

\subsection{Environment}

The economy involves two types of agents indexed by $i=1,2$. Both types are infinitely-lived, and there exist $N_{i}$ identical agents of type $i$, where $N_{i}>0$ for all $i$. Time is indexed by $t \in\{0,1, \ldots\}$.

There are two commodities at each time: a factor of production, labor, and a nonstorable consumption good, apple. Neither type 1 nor type 2 agents value leisure. A representative agent of type $i$ seeks to maximize $\sum_{t=0}^{\infty} \beta_{i}^{t} U_{i}\left(c_{i, t}\right)$, where $\beta_{i} \in(0,1)$ is the discount factor, $c_{i, t}$ is period-t consumption and $U_{i}($.$) is the$ instantaneous utility function of each type $i$ agent. We assume that $U_{i}^{\prime}()>$.0 and $U_{i}^{\prime \prime}()<$.0 .

Each type $i$ agent has a labor endowment $\bar{L}_{i}$ where $\bar{L}_{1}>0$ and $\bar{L}_{2} \geq 0$, and a technology $f_{i}(L)$ to convert labor into apples. We assume that type 2 agents have a superior technology. Production functions represent decreasing returns to scale (DRTS) technologies, and satisfy $f_{i}()>0,. f_{i}^{\prime}()>$.0 and $f_{i}^{\prime \prime}()<$.0 for all $i$. We also assume:

A.1. $\lim _{L \downarrow 0} f_{i}^{\prime}(L)=\infty$ for all $i=1,2$.

A.2. $f_{2}^{\prime}(L)>f_{1}^{\prime}(L)$ for all $L>0$.

A.3. $f_{2}^{\prime}\left(\bar{L}_{2}\right)>f_{1}^{\prime}\left(\bar{L}_{1}\right)$.

We denote and describe a society by $\mathcal{S}=\left\{N_{i}, \bar{L}_{i}, U_{i}, \beta_{i}, f_{i} \mid i=1,2\right\}$.

\subsection{Money and the government}

In each period, there exists a positive quantity of money supply in the economy. Let $M_{t}$ denote the aggregate money stock at the beginning of period $t$. We assume that the economy starts with $M_{0}=\bar{M}>0$. Each type $i$ agent is born with $M_{i, 0}$ units of currency where

$$
N_{1} M_{1,0}+N_{2} M_{2,0}=\bar{M}
$$

Total money stock evolves, for all $t \geq 0$, according to

$$
M_{t+1}=(1+\alpha) M_{t} \text {, with } \alpha>-1,
$$

which is fully anticipated by all type of agents in the economy. The government sustains the targeted money growth by appropriately distributing lump-sum monetary transfers to (or imposing money taxes on) the agents in the economy. Here, we define $\tau_{i}$ as the ratio of the total money transfer type $i$ agents receive to the total money stock present in the economy at the beginning of each period. For each $\alpha>-1$, we define the associated set $\mathcal{T}_{\alpha}$, containing all distribution of transfer rates that yield the targeted money growth, as follows:

$$
\mathcal{T}_{\alpha}=\left\{\left(\tau_{1}, \tau_{2}\right) \mid \tau_{1}+\tau_{2}=\alpha, \text { and } \tau_{1}, \tau_{2} \in \mathbb{R}\right\}
$$




\subsection{Trade institution}

A trade institution for a given society is the description of choice variables for each type of agents, price variables, constraints on the given choice variables determined by given prices, and a feasibility requirement for the collective choices of agents.

Choice variables of type $i$ agents in period $t \geq 0$ :

$c_{i, t} \quad$ : consumption,

$L_{i, t} \quad$ : labor demand ((+) demand, (-) supply),

$q_{i, t} \quad$ : apple demand ((+) demand, (-) supply),

$M_{i, t+1}:$ money carried over to period $t+1$.

Prices in period $t \geq 0$ :

$w_{t}$ : nominal wage rate,

$p_{t}:$ nominal apple price.

2.3.1 Transactions There exist three markets: the money, labor and good (apple) markets. The price of the money is taken as numeraire at all times; so all other prices are stated in terms of money. We also assume that the labor market opens before the good market. ${ }^{3}$

The timing of transactions, which is also shown in Fig. 1, can be described as follows:

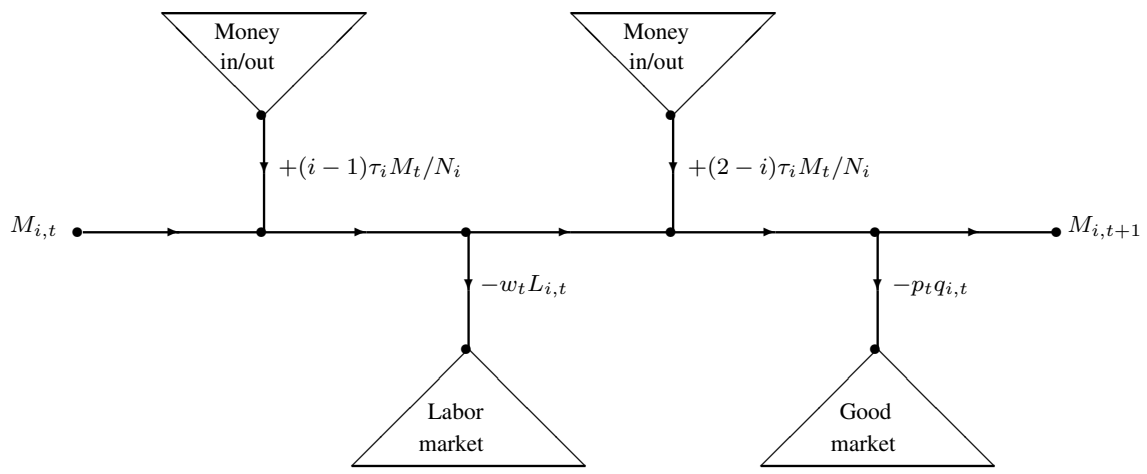

Fig. 1. Cash flow of type $i$ agents in period $t+1$

- Each agent of type $i$ starts period $t$ with the money balance $M_{i, t}$.

- Just before the labor market opens, $(i-1)\left(\tau_{i} / N_{i}\right) M_{t}$ units of currency are transferred, by the government, to each type $i$ agent. (Here, type 1 agents do not receive transfers.)

3 Başçı and Saglam (2003) shows that if the good market opens before the factor market, the competitive outcomes are the same as those obtained in the absence of such cash constraints. Liquidity constraints have some real effects only if the factor market opens before the good market. 
- Labor market opens. Each agent of type $i$ enters the labor market with $M_{i, t}+$ $(i-1)\left(\tau_{i} / N_{i}\right) M_{t}$ units of currency at time $t$. In the labor market, trade occurs at the nominal wage rate $w_{t}$. All wage bills are paid before the good market opens.

- Apple production takes place with the purchased and unsold labor.

- After the harvest of apples $(2-i)\left(\tau_{i} / N_{i}\right) M_{t}$ units of currency are transferred, by the government, to each agent of type $i$. (Here, only type 1 agents receive transfers. $)^{4}$

- Good market opens. Each agent of type $i$ enters the market with

$$
M_{i, t}+(i-1) \frac{\tau_{i}}{N_{i}} M_{t}-w_{t} L_{i, t}+(2-i) \frac{\tau_{i}}{N_{i}} M_{t}=M_{i, t}+\frac{\tau_{i}}{N_{i}} M_{t}-w_{t} L_{i, t}
$$

units of currency. In the good market, apple is bought and sold at the nominal price $p_{t}$. These transactions determine the next period's money balance of each agent as

$$
M_{i, t+1}=M_{i, t}+\frac{\tau_{i}}{N_{i}} M_{t}-w_{t} L_{i, t}-p_{t} q_{t}
$$

2.3.2 Agents' problems Given the endowment structure described above, a net supply rule $\alpha>-1$, a pair of transfer rates $\left(\tau_{1}, \tau_{2}\right) \in \mathcal{T}_{\alpha}$ and a sequence of strictly positive prices $\left\{w_{t}, p_{t}\right\}_{t=0}^{\infty}$, a representative agent of type $i$ faces the following problem $\left(P_{i}\right)$ :

$$
\begin{aligned}
& \left(P_{i}\right) \quad \max \sum_{t=0}^{\infty} \beta_{i}^{t} U_{i}\left(c_{i, t}\right) \text { subject to, for all } t \\
& c_{i, t}=f_{i}\left(\bar{L}_{i}+L_{i, t}\right)+q_{i, t} \\
& -\bar{L}_{i} \leq L_{i, t} \leq \frac{M_{i, t}+(i-1)\left(\tau_{i} / N_{i}\right) M_{t}}{w_{t}} \\
& -f_{i}\left(\bar{L}_{i}+L_{i, t}\right) \leq q_{i, t} \leq \frac{M_{i, t}+\left(\tau_{i} / N_{i}\right) M_{t}-w_{t} L_{i, t}}{p_{t}} \\
& M_{i, t+1}=M_{i, t}+\left(\tau_{i} / N_{i}\right) M_{t}-w_{t} L_{i, t}-p_{t} q_{i, t} \\
& M_{i, t+1}+(i-1)\left(\tau_{i} / N_{i}\right) M_{t+1} \geq 0 \\
& M_{i, t+1}-w_{t+1} L_{i, t+1}+\left(\tau_{i} / N_{i}\right) M_{t+1} \geq 0 \\
& M_{i, 0} \geq 0 \quad \text { is given. }
\end{aligned}
$$

Equation (1) states that per-period consumption is the sum of the home production and the apple purchases (sales, if negative). The upper bound in (2) comes from the cash-in-advance requirement and the fact that the labor market opens first. The lower bound (if multiplied by -1 ) is the maximum amount of labor that can be supplied. The constraint (3) on apple purchases can be similarly read. Constraint (4) describes the cash flow across successive periods, whereas (5) and (6) indicate that agents of both types must hold sufficient amount of money to pay any taxes charged by the government.

${ }^{4}$ In Sect. 6, we discuss the welfare effects of alternative timings for the distribution of monetary transfers. 
We call the above trade institution financially constrained by the fact that a producer is restricted in its labor purchases with the amount of money he holds. This financial restriction limits the participation of firms in both factor and output markets, despite the presence of positive marginal profitability. By a financially constrained production economy we mean a society $\mathcal{S}$ operating under a financially constrained trade institution, and denote it by $\mathcal{F C} \mathcal{E}$.

\subsection{Monetary equilibrium}

The set of sequences $\left\{p_{t}, w_{t}, c_{i, t}, L_{i, t}, q_{i, t}, M_{i, t+1} \mid i=1,2\right\}_{t=0}^{\infty}$ is a stationary monetary competitive equilibrium (SMCE) of the financially constrained production economy $\mathcal{F C E}$, if $w_{t}, p_{t}>0$ for all $t$, and

(i) for each $i,\left\{c_{i, t}, L_{i, t}, q_{i, t}, M_{i, t+1}\right\}_{t=0}^{\infty}$ solves $\left(P_{i}\right)$ under the sequence $\left\{w_{t}, p_{t}\right\}_{t=0}^{\infty}$,

(ii) $c_{i, t+1} / c_{i, t}=L_{i, t+1} / L_{i, t}=q_{i, t+1} / q_{i, t}=1$ for all $i$ and $t$,

(iii) $w_{t+1} / w_{t}=p_{t+1} / p_{t}=M_{i, t+1} / M_{i, t}=1+\alpha$ for all $i$ and $t$,

(iv) $N_{1} L_{1, t}+N_{2} L_{2, t}=0$ for all $t$,

(v) $N_{1} q_{1, t}+N_{2} q_{2, t}=0$ for all $t$,

(vi) $N_{1} M_{1, t+1}+N_{2} M_{2, t+1}=M_{t+1}$ for all $t$.

In equilibrium, we expect type 1 agents to sell and type 2 agents to buy labor, because of the assumed marginal productivity gap. However, due to DRTS technologies, each type 1 agent will always be left with some residual labor to use in his own production plant after supplying an optimal amount to the market at the given wage rates. Thus, both types of agents will happen to produce in equilibrium. Nevertheless, we will use the label "firm" for type 2 agents, who own superior technologies, and the label "worker" for type 1 agents, who offer some part of their labor to firms.

\section{Characterization of equilibria}

We can eliminate $c_{i, t}$ and $q_{i, t}$ from $\left(P_{i}\right)$, using the equality constraints (1) and (4). Then, we can concentrate on the clearing of the labor and money markets only, since the good market will automatically clear as well, thanks to a version of Walras' law. The reduced form problem, $\left(P_{i}^{\prime}\right)$ of each type $i$ agent can be expressed as

$$
\left(P_{i}^{\prime}\right) \max \sum_{t=0}^{\infty} \beta_{i}^{t} U_{i}\left(f_{i}\left(\bar{L}_{i}+L_{i, t}\right)-\frac{w_{t}}{p_{t}} L_{i, t}+\frac{M_{i, t}+\left(\tau_{i} / N_{i}\right) M_{t}-M_{i, t+1}}{p_{t}}\right)
$$

subject to, for all $t$

$$
\begin{aligned}
& -\bar{L}_{i} \leq L_{i, t} \leq \frac{M_{i, t}+(i-1)\left(\tau_{i} / N_{i}\right) M_{t}}{w_{t}} \\
& 0 \leq M_{i, t+1} \leq M_{i, t}+\left(\tau_{i} / N_{i}\right) M_{t}-w_{t} L_{i, t}+p_{t} f_{i}\left(\bar{L}_{i}+L_{i, t}\right)
\end{aligned}
$$




$$
\begin{aligned}
& M_{i, t+1}+(i-1)\left(\tau_{i} / N_{i}\right) M_{t+1} \geq 0 \\
& M_{i, t+1}-w_{t+1} L_{i, t+1}+\left(\tau_{i} / N_{i}\right) M_{t+1} \geq 0 \\
& M_{i, 0} \geq 0 \text { is given. }
\end{aligned}
$$

Proposition 1. Assume $\beta_{1} \leq \beta_{2} f_{2}^{\prime}\left(\bar{L}_{2}\right) / f_{1}^{\prime}\left(\bar{L}_{1}\right)$. Then, there exists SMCE of a $\mathcal{F C E}$ only if

$$
\begin{aligned}
1+\alpha & \in\left[\max \left\{\beta_{1}, \beta_{2}\right\}, \beta_{2} f_{2}^{\prime}\left(\bar{L}_{2}\right) / f_{1}^{\prime}\left(\bar{L}_{1}\right)\right), \\
\frac{w_{t}}{p_{t}} & =\frac{\beta_{2} f_{2}^{\prime}\left(\bar{L}_{2}+L_{2, t}\right)}{1+\alpha}, \\
M_{1,0} & =\mu \bar{M} / N_{1}, \text { where } \\
\mu & \in \begin{cases}\{0\} \text { if } 1+\alpha>\beta_{1}, \\
{[0,1] \text { if } 1+\alpha=\beta_{1} .}\end{cases}
\end{aligned}
$$

Proof. The Proof is in the Appendix.

We note that sufficiently high inflation rates $\left(1+\alpha\right.$ above $\left.\beta_{2} f_{2}^{\prime}\left(\bar{L}_{2}\right) / f_{1}^{\prime}\left(\bar{L}_{1}\right)\right)$ or even very low deflation rates $\left(1+\alpha\right.$ slightly below the maximum of $\beta_{1}$ and $\beta_{2}$ that may be close to one) may lead to the breakdown of the monetary market economy. If $1+\alpha>\beta_{2} f_{2}^{\prime}\left(\bar{L}_{2}\right) / f_{1}^{\prime}\left(\bar{L}_{1}\right)$, then real wage rates would be below the marginal productivity of workers in firms' plants. In that case, type 1 agents would prefer not to supply labor. On the other extreme, if $1+\alpha<\beta_{2}$, real wage rates would be above the marginal productivity in firms' plants; thus type 2 agents would not hire labor. Clearly, in none of the above cases can an equilibrium exist. Moreover, a supply rule such as $1+\alpha<\beta_{1}$ is not consistent with a stationary equilibrium, since workers, upon anticipating such a deflationary policy, would start to hoard money in every period $t$. This would, of course, leave firms out of the required working capital after a finite time.

It is interesting that equilibrium exists only if workers are, in general, paid less than their marginal products. This result, which is not observed in Arrow-Debreu economies, arises in our model due to the market imperfection we impose, namely, cash-in-advance constraints in production.

The parameter $\mu$ in Proposition 1 denotes the share of the initial money endowments of type 1 agents in the total initial money stock of the economy. To see why the distribution of the initial money stock matters for the existence of a stationary equilibrium, note that under the equilibrium wages workers buy in the good markets, only. So, for workers, the net rate of return from carrying over an infinitesimal unit of currency from period $t$ to period $t+1$, under a stationary consumption plan is $\beta_{1}(1+\alpha)^{-1}-1$. It is obvious that a plan with constant positive money holding in each period cannot be optimal for workers if $1+\alpha>\beta_{1}$, since they can be better-off by reducing their money holdings, and thereby increasing their consumptions, in each period. 
Proposition 2. Assume $\beta_{1} \leq \beta_{2} f_{2}^{\prime}\left(\bar{L}_{2}\right) / f_{1}^{\prime}\left(\bar{L}_{1}\right), 1+\alpha \in\left[\max \left\{\beta_{1}, \beta_{2}\right\}\right.$, $\left.\beta_{2} f_{2}^{\prime}\left(\bar{L}_{2}\right) / f_{1}^{\prime}\left(\bar{L}_{1}\right)\right)$ and $\left(\tau_{1}, \tau_{2}\right) \in \mathcal{T}_{\alpha}$. Let $M_{1,0}=\mu \bar{M} / N_{1}$, where $\mu$ satisfies (16). Then,

(i) there exists $\operatorname{SMCE}\left\{w_{t}, p_{t}, L_{i, t}, q_{i, t}, c_{i, t}, M_{i, t+1} \mid i=1,2\right\}_{t=0}^{\infty}$ if

$$
\begin{aligned}
& \sigma>\frac{1}{2}, \\
& \frac{1-\sigma}{1+\alpha}\left(1-\mu+\tau_{2}\right) \leq 1-\mu<\frac{\sigma}{1+\alpha}\left(1-\mu+\tau_{2}\right),
\end{aligned}
$$

where $\sigma=w_{0} N_{1} \bar{L}_{1} /\left(\left(1-\mu+\tau_{2}\right) M_{0}\right)$;

(ii) SMCE, whenever exists, satisfies (19)-(27) for all t:

$$
\begin{aligned}
& w_{t}=\frac{\sigma\left(1-\mu+\tau_{2}\right) M_{t}}{N_{2} L_{2, t}} \\
& \sigma \in\left\{\begin{array}{l}
\{1\} \quad \text { if } 1+\alpha>\beta_{2} \\
(0,1] \text { if } 1+\alpha=\beta_{2}
\end{array}\right. \\
& p_{t}=\frac{(1+\alpha) w_{t}}{\beta_{2} f_{2}^{\prime}\left(\bar{L}_{2}+L_{2, t}\right)} \\
& f_{1}^{\prime}\left(\bar{L}_{1}+L_{1, t}\right)=\frac{w_{t}}{p_{t}} \\
& L_{2, t}=-\frac{N_{1} L_{1, t}}{N_{2}} \\
& q_{i, t}=-\left(1-\frac{1}{\sigma}+\frac{1+\alpha}{\sigma\left(1-\mu+\tau_{2}\right)}\right) \frac{w_{t}}{p_{t}} L_{i, t}, \quad i=1,2 \\
& c_{i, t}=f_{i}\left(\bar{L}_{i}+L_{i, t}\right)+q_{i, t}, \quad i=1,2 \\
& M_{1, t}=\mu \frac{M_{t}}{N_{1}} \\
& M_{2, t}=(1-\mu) \frac{M_{t}}{N_{2}}
\end{aligned}
$$

Proof. The Proof is in the Appendix.

There exists a unique equilibrium if $1+\alpha>\beta_{2}$, whereas a continuum of equilibria if $1+\alpha=\beta_{2}$. To see this clearly, notice that the parameter $\sigma$ denotes the fraction of the net money holdings type 2 agents spend in the labor market. In equilibrium, type 2 agents find it optimal to spend all their money holdings $(\sigma=1)$ in the labor market in each period, if the money is deflated at a lower rate than they discount the unit time period $\left(-\alpha<1-\beta_{2}\right)$. On the other hand, when the deflation rate equals their time discount $\left(-\alpha=1-\beta_{2}\right)$, any positive fraction of the money holdings $(\sigma \in(0,1])$ spent in the labor market yields the same utility to a type 
2 agent. Under this particular deflation rate, there exists a distinct equilibrium for each $\sigma$.

\section{Analysis of equilibria}

We observe from (21) that there is a negative relationship between the equilibrium real wage rate and the money growth rate. The intuitive argument underlying this fact is as follows: Increasing the current consumption at time $t$ by reducing the savings for the next period by $\Delta M$ units yields to a firm a marginal utility of $U^{\prime}\left(c_{t}\right)\left(\Delta M / p_{t}\right)$, where $\Delta M / p_{t}$ is the amount of the additional consumption. On the other hand, with $\Delta M$ units of decrease in its initial money holdings of period $t+1$, the labor demand of the firm falls by $\Delta M / w_{t+1}$ units, which yields a drop of $f_{2}^{\prime}\left(\bar{L}_{2}+L_{2, t+1}\right) \Delta M / w_{t+1}$ units in the output. The decrease in the utility of the firm due to the fall in output at time $t+1$ then becomes $\beta_{2} U_{2}^{\prime}\left(c_{2, t+1}\right) f_{2}^{\prime}\left(\bar{L}_{2}+\right.$ $\left.L_{2, t+1}\right) \Delta M / w_{t+1}$. In an equilibrium, where the consumption and the effective labor are constant and nominal prices and wages grow at the money inflation rate, the net marginal utility to the firm from transferring money between consecutive periods becomes zero only if $w_{t+1} \equiv(1+\alpha) w_{t}=\beta_{2} f_{2}^{\prime}\left(\bar{L}_{2}+L_{2, t+1}\right) p_{t}$.

The negative relationship between the real wages and the money growth rate provides a channel for inflation to affect the output and the income distribution. The total output that we denote by $Q_{t}$ satisfies

$$
Q_{t}=N_{1} f_{1}\left(\bar{L}_{1}-N_{2} L_{2, t} / N_{1}\right)+N_{2} f_{2}\left(\bar{L}_{2}+L_{2, t}\right) .
$$

Recalling from (21), (22) and (23) that the equilibrium wage rate satisfies

$$
\frac{w_{t}}{p_{t}}=\frac{\beta_{2} f_{2}^{\prime}\left(\bar{L}_{2}+L_{2, t}\right)}{1+\alpha}=f_{1}^{\prime}\left(\bar{L}_{1}-N_{2} L_{2, t} / N_{1}\right),
$$

we obtain the following result.

Proposition 3. In equilibrium, both the real wage rate and the total output are decreasing in the money growth rate.

Proof. The Proof is in the Appendix.

The policy implication of the above proposition is that anticipated contractionary monetary policies may be used to yield an expansion of the economy, which, naturally, raises the issue of the optimal money supply rule that will be discussed in Sect. 5.

The next proposition shows that the lower is the rate firms discount the unit time period or the higher is the size of the physical endowments, the higher is the level of the output produced in the economy.

Proposition 4. In equilibrium, both the real wage rate and the total output are increasing in $\beta_{2}, \bar{L}_{1}$ and $\bar{L}_{2}$.

Proof. Omitted as it is similar to the proof of Proposition 3. 
Monetary policies have effects on the income distribution as well. The equilibrium consumption of each type $i$ agent can be written as

$$
c_{i, t}=f_{i}\left(\bar{L}_{i}+L_{i, t}\right)-\left(1-\frac{1}{\sigma}+\frac{1+\alpha}{\sigma\left(1-\mu+\tau_{2}\right)}\right) \frac{\beta_{2} f_{2}^{\prime}\left(\bar{L}_{2}+L_{2, t}\right)}{1+\alpha} L_{i, t}
$$

for all $t$. We observe that given $\beta_{1} \leq \beta_{2}, 1+\alpha=\beta_{2}$ and a feasible pair $\left(\tau_{1}, \tau_{2}\right) \in$ $\mathcal{T}_{\beta_{2}-1}$, the consumption of the worker type, $c_{1, t}$, is increasing while the consumption of the firm type, $c_{2, t}$, is decreasing in $\mu$, i.e., a type consumes more in equilibrium if it holds a higher share of the total money supply in each period.

On the other hand, given the discount factors $\beta_{1}<\beta_{2}$, a deflation rate $1+\alpha=$ $\beta_{2}$ and a feasible pair of taxes $\left(\tau_{1}, \tau_{2}\right) \in \mathcal{T}_{\beta_{2}-1}$ satisfying $\tau_{1}<0$, the smaller $\sigma$ in its admissible interval $(0,1]$, the lower the nominal wage rate and the apple price, and thus the lower (the higher) the consumption of the worker (firm) type. The intuition underlying this result is that with $\sigma$ being lower, firms will sell less in the good market if $\tau_{1}<0$, since workers will spend a smaller quantity of their real money balances in the good market due to the real increase in the taxes they must pay.

We also observe that for a given money supply rule, the per-period consumption and hence the lifetime utility of each type is increasing (decreasing) in the transfer that this particular type (the other type) receives.

\section{Optimal monetary policy}

A money supply rule is called optimal if it maximizes the total output among all feasible supply rules supporting SMCE. In our model, the optimal money supply rule is uniquely determined by $1+\alpha=\max \left\{\beta_{1}, \beta_{2}\right\}$, which directly follows from Proposition 3.

We will now look for the supply rules under which SMCE coincides with the equilibrium of a sequence of spot markets (SSME). For the version of our model, which involves no market friction within periods and hence allows for spot commodity contracts, a SSME consists of a trading plan, and prices for each traded good and factor, under which spot optimization problems of all agents are solved, all markets are cleared, and each worker is paid the marginal product of the factor he supplies.

Formally, the list of sequences $\left\{\hat{w}_{t}, \hat{p}_{t}, \hat{L}_{i, t}, \hat{q}_{i, t}, \hat{c}_{i, t} \mid i=1,2\right\}_{t=0}^{\infty}$ is a SSME if

$$
\begin{aligned}
& \hat{w}_{t} / \hat{p}_{t}=f_{2}^{\prime}\left(\bar{L}_{2}+\hat{L}_{2, t}\right)=f_{1}^{\prime}\left(\bar{L}_{1}+\hat{L}_{1, t}\right) \\
& N_{1} \hat{L}_{1, t}+N_{2} \hat{L}_{2, t}=0 \\
& \hat{q}_{i, t}=-\frac{\hat{w}_{t}}{\hat{p}_{t}} \hat{L}_{i, t} \text { for all } i \\
& \hat{c}_{i}=f_{i}\left(\bar{L}_{i}+\hat{L}_{i, t}\right)+\hat{q}_{i, t} \text { for all } i
\end{aligned}
$$

Proposition 5. Assume $\beta_{1} \leq \beta_{2} f_{2}^{\prime}\left(\bar{L}_{2}\right) / f_{1}^{\prime}\left(\bar{L}_{1}\right)$. Let $\left\{w_{t}, p_{t}, L_{i, t}, q_{i, t}, c_{i, t}\right.$, $\left.M_{i, t+1} \mid i=1,2\right\}_{t=0}^{\infty}$ be a SMCE associated with a feasible monetary policy 
$\left(\alpha, \tau_{1}, \tau_{2}\right)$ and a distribution $\left(M_{1,0}, M_{2,0}\right)$. Then this SMCE is a SSME if and only if, (i) $\beta_{1} \leq \beta_{2}$, (ii) $1+\alpha=\beta_{2}$, and (iii) $\tau_{2}=\beta_{2}+\mu-1$, where $\mu=M_{1,0} / M_{0}$.

Proof. The Proof is in the Appendix.

From Proposition 5 it follows that the monetary policy which brings the economy to a second best equilibrium, satisfies $\tau_{2}=\alpha=\beta_{2}-1$ if $\beta_{2}>\beta_{1}$. ${ }^{5}$ In other words, when firms are more patient than workers, the optimal money supply rule yields productively efficient outcomes if, and only if, all money taxes are charged to firms.

\section{Alternative timings in the distribution of monetary transfers}

We will now discuss whether the other possible timings that the government may follow to implement its targeted money supply rule affect the equilibrium outcome.

For all periods, let $l$ and $g$ respectively denote the instants the labor market and the good market open in each period according to the sequencing of market transactions defined in Sect. 2. Define the set $\Theta=\{l, g\}$. Let the ordered pair $\left(\theta_{1}, \theta_{2}\right) \in \Theta \times \Theta$ denote a constant timing rule according to which type 1 and type 2 agents, respectively, receive their transfers just before the instants $\theta_{1}$ and $\theta_{2}$ in each period.

In the model that we have analyzed above, an agent receives money transfer just before the good market opens if he is of type 1 , and just before the labor market opens if he is of type 2 ; i.e. we have so far assumed $\left(\theta_{1}, \theta_{2}\right)=(g, l)$ in all periods. We will below consider the other cases.

For all $\theta_{2} \in \Theta$ and for all feasible $\tau_{1} \geq 0$, the set of SMCE is the same under both $\left(l, \theta_{2}\right)$ and $\left(g, \theta_{2}\right)$ since type 1 agents do not buy labor under the SMCE wages. However, if $\tau_{1}<0$, the set of money supply rules supporting SMCE is extremely thin under the timing rule $\left(l, \theta_{2}\right)$ for all $\theta_{2} \in \Theta$, since charging money taxes to type 1 agents at the instant $l$ is not feasible unless $1+\alpha=\beta_{1}$, which is the unique money growth rate allowing $M_{1, t}>0$ for all $t$. It is also apparent that the optimal monetary policy remains the same as described in Proposition 5 and leads to the same equilibrium outcome under both $\left(l, \theta_{2}\right)$ and $\left(g, \theta_{2}\right)$ for all $\theta_{2} \in \Theta$.

The timing of monetary transfers does not seem to matter also when type 2 agents pay money taxes $\left(\tau_{2} \leq 0\right)$. In this case, the set of SMCE is the same under both $\left(\theta_{1}, l\right)$ and $\left(\theta_{1}, g\right)$ for all $\theta_{1} \in \Theta$, since type 2 agents receive their sales revenues after the good market closes. However, the conclusions drastically change if $\tau_{2}>0$. To see this, notice first that the equilibrium real wage rate and the employment level remain the same for all $\left(\theta_{1}, \theta_{2}\right) \in \Theta \times \Theta$. However, the nominal wage rates, $w_{t}$, are lower under the timing $\left(\theta_{1}, g\right)$ than under $\left(\theta_{1}, l\right)$, since firms will have lower cash holdings to spend in the labor market if they receive monetary transfers later on. It follows that the prices, $p_{t}$, are lower, too, under the timing $\left(\theta_{1}, g\right)$. The fall

5 Clearly, this is different from a proper Arrow-Debreu equilibrium in which future commodity contracts can also be traded. In case $\beta_{2} \neq \beta_{1}$, the consumption of the relatively patient agent would be increasing, while that of the impatient one would be decreasing over time, since borrowing and lending are possible. 
in the prices exceeds (in percentage terms) the fall in the money held by workers just before the good market opens, since workers, at this time instant, have their initial cash holdings plus transfers (minus taxes), in addition to the money wages they earned in the labor market. This further implies that under the rule $\left(\theta_{1}, g\right)$ workers (firms) can consume more (less) apples than under the rule $\left(\theta_{1}, l\right)$. Clearly, this observation defines a preference relation over the two timing rules from the viewpoints of the two interest groups in the economy. If firms receive positive monetary transfers, workers prefer the rule $\left(\theta_{1}, g\right)$ whereas firms prefer $\left(\theta_{1}, l\right)$ for all $\theta_{1} \in \Theta$. By the described dependence of the income distribution on the level and timing of monetary transfers that firms receive, one can argue that the optimal monetary policy, which is clearly independent from the timings we consider, also leads to the same outcome under the two timings if $\beta_{2}>\beta_{1}$, for in that case the optimal supply rule involves $\tau_{2}=\beta_{2}-1$, which is negative. However, if $\beta_{2}=\beta_{1}$, the outcome that the optimal monetary policy will lead to may and may not change with the timing of monetary transfers since the sign of the optimal transfer rule $\tau_{2}=\beta_{2}+\mu-1$ becomes indeterminate due to the multiplicity of equilibria.

\section{Concluding remarks}

In this paper, we studied the consequences of alternative monetary policies in a deterministic model with two types of agents. In the model, fiat money is used by firms to finance their wage expenses, so that money is demanded by the "high-tech" type who plays the role of a firm in our model. We observed that the presence of cash-in-advance constraints in the labor market limits the demand for labor, so that an equilibrium with the real wage rate below the marginal productivity of labor can be sustained.

Economies with a finite number of infinitely lived agents in a complete markets setup are known to exhibit Pareto efficiency under quite weak assumptions. If, however, there are cash constraints on transactions, so that fiat money is valued in equilibrium, one does not expect to observe efficiency of equilibrium allocations. Grandmont and Younes (1973) present an example of an inefficient monetary economy without production. Woodford (1990) provides examples from the literature of cash-in-advance models that may and may not lead to Pareto efficient allocations under careful monetary policy. For example, under the institutional setups studied by Sargent (1987, Chapts. 5 and 6), where there are no credit goods, it turns out to be possible to restore efficiency through a deflationary monetary policy.

In our context, for different rates of time preference across agents, even under the optimal contractionary monetary policy of taxing only the firm types at a certain rate, the set of equilibria turn out to be different from the set of Arrow-Debreu (AD) equilibria. If a complete set of $\mathrm{AD}$ contracts were available, then, the equilibrium consumption plan of the patient type would be monotone increasing, while that of the impatient one would be decreasing. The presence of cash-in-advance and borrowing constraints, however, supports a constant consumption plan for each type as an equilibrium.

Specifically, inflation distorts the functional distribution of income by reducing the real wage rate. So inflation seems to hurt wage earners and help firms. 
However, the way that the monetary expansion is conducted has important welfare consequences. Careful monetary transfer policies may partially remedy the adverse income distribution effects, by compensating the wage earners. For example if all the freshly created money is transferred to workers, then they will not be hurt much by inflation. Yet, the real wage and the related output distortion will remain intact even under zero inflation.

\section{Appendix}

Proof of Proposition 1. Type $i$ agents face the reduced-form problem $P_{i}^{\prime}$. Let $\left\{w_{t}, p_{t}, L_{i, t}, q_{i, t}, c_{i, t}, M_{i, t+1} \mid i=1,2\right\}_{t=0}^{\infty}$ be a SMCE. We claim that $w_{t} / p_{t}$ supports SMCE only if $w_{t} / p_{t} \in\left(f_{1}^{\prime}\left(\bar{L}_{1}\right), f_{2}^{\prime}\left(\bar{L}_{2}\right)\right)$. First suppose $w_{t} / p_{t} \leq f_{1}^{\prime}\left(\bar{L}_{1}\right)$ for some $t$. Then $L_{1, t} \geq 0$ and $L_{2, t}>0$, violating the labor market clearing. Next suppose $w_{t} / p_{t} \geq f_{2}^{\prime}\left(\bar{L}_{2}\right)$. Then $L_{1, t}=-\bar{L}_{1}$ and $L_{2, t} \leq 0$, again a contradiction. If $w_{t} / p_{t}>f_{1}^{\prime}\left(\bar{L}_{1}\right)$, then there exists $L_{1, t} \in\left(-\bar{L}_{1}, 0\right)$ that solves $f_{1}^{\prime}\left(\bar{L}_{1}+L_{1, t}\right)=$ $w_{t} / p_{t}$, by assumption A.1. It is also true that $w_{t} / p_{t} \leq f_{2}^{\prime}\left(\bar{L}_{2}+L_{2, t}\right)$, for the optimality of $L_{2, t} \geq 0$. Therefore SMCE exists only if

$$
w_{t} / p_{t}=f_{1}^{\prime}\left(\bar{L}_{1}+L_{1, t}\right) \leq f_{2}^{\prime}\left(\bar{L}_{2}+L_{2, t}\right)
$$

for all $t$. Inserting $L_{1, t}<0$ into the problem $\left(P_{1}^{\prime}\right)$, we obtain the Euler condition, associated with control $\left(1 / p_{t}\right) M_{1, t+1}$, as

$$
U_{1}^{\prime}\left(c_{1, t}\right) \geq \frac{\beta_{1} p_{t}}{p_{t+1}} U_{1}^{\prime}\left(c_{1, t+1}\right)
$$

which is satisfied by a stationary plan $c_{1, t+1}=c_{1, t}$ under the stationary prices $p_{t+1}=(1+\alpha) p_{t}$, if and only if $1+\alpha \geq \beta_{1}$, as required by (13). Then, a plan $\left\{M_{1, t}\right\}_{t=0}^{\infty}$ is consistent with SMCE only if $M_{1, t}=\mu M_{t} / N_{1}$ for all $t$ where $\mu$ satisfies (16). To show that the rest of (13) as well as (14) are necessary, we consider the following two cases.

Case 1. $f_{1}^{\prime}\left(\bar{L}_{1}+L_{1, t}\right)=f_{2}^{\prime}\left(\bar{L}_{2}+L_{2, t}\right)=w_{t} / p_{t}$.

We can solve for $L_{1, t} \in\left(\bar{L}_{1}, 0\right)$ in the above equation using $L_{2, t}=$ $-N_{1} L_{1, t} / N_{2}$, and next calculate $w_{t} / p_{t}$. Since $f_{2}^{\prime}\left(\bar{L}_{2}+L_{2, t}\right)=w_{t} / p_{t}$, cashin-advance constraint is not binding for type 2 agents. So, the Euler condition associated with control $\left(1 / p_{t}\right) M_{2, t+1}$, obtained from $\left(P_{2}^{\prime}\right)$, is

$$
U_{2}^{\prime}\left(c_{2, t}\right)=\frac{\beta_{2} p_{t}}{p_{t+1}} U_{2}^{\prime}\left(c_{2, t+1}\right) \text { for all } t .
$$

A stationary plan $c_{2, t+1}=c_{2, t}$ satisfies Euler condition under the prices $p_{t+1}=$ $(1+\alpha) p_{t}$, only if $1+\alpha=\beta_{2}$.

Case 2. $f_{1}^{\prime}\left(\bar{L}_{1}+L_{1, t}\right)=w_{t} / p_{t}<f_{2}^{\prime}\left(\bar{L}_{2}+L_{2, t}\right)$. 
This case arises only if the cash-in-advance constraint is binding for type 2 agents. After inserting $L_{2, t}=\left(M_{2, t}+\tau_{2} M_{t}\right) / w_{t}$ into $\left(P_{2}^{\prime}\right)$, we obtain the Euler condition, associated with control $\left(1 / p_{t}\right) M_{2, t+1}$, as

$$
U_{2}^{\prime}\left(c_{2, t}\right)=\frac{\beta_{2} p_{t}}{w_{t+1}} f_{2}^{\prime}\left(\bar{L}_{2}+L_{2, t+1}\right) U_{2}^{\prime}\left(c_{2, t+1}\right) \text { for all } t .
$$

A stationary plan with $c_{2, t+1}=c_{2, t}$ and $L_{2, t+1}=L_{2, t}$ satisfies Euler condition under the stationary wages $w_{t+1}=(1+\alpha) w_{t}$, only if $w_{t} / p_{t}=\beta_{2} f_{2}^{\prime}\left(\bar{L}_{2}+\right.$ $\left.L_{2, t}\right) /(1+\alpha)$. Now, using

$$
w_{t} / p_{t}=f_{1}^{\prime}\left(\bar{L}_{1}+L_{1, t}\right)=\beta_{2} f_{2}^{\prime}\left(\bar{L}_{2}+L_{2, t}\right) /(1+\alpha)
$$

and $L_{1, t}=-N_{2} L_{2, t} / N_{1}$, we can solve for $L_{1, t}$ and $L_{2, t}$, and calculate $w_{t} / p_{t}$. We have $L_{1, t}<0$ and $L_{2, t}>0$, since $w_{t} / p_{t}>f_{1}^{\prime}\left(\bar{L}_{1}\right)$. Then, it is true that

$$
\frac{f_{1}^{\prime}\left(\bar{L}_{1}+L_{1, t}\right)}{f_{1}^{\prime}\left(\bar{L}_{1}\right)}>\frac{f_{2}^{\prime}\left(\bar{L}_{2}+L_{2, t}\right)}{f_{2}^{\prime}\left(\bar{L}_{2}\right)} .
$$

Multiplying both sides of the above inequality by $\beta_{2}$ and rearranging yields

$$
f_{1}^{\prime}\left(\bar{L}_{1}+L_{1, t}\right)>\frac{f_{1}^{\prime}\left(\bar{L}_{2}\right)}{\beta_{2} f_{2}^{\prime}\left(\bar{L}_{2}\right)} \beta_{2} f_{2}^{\prime}\left(\bar{L}_{2}+L_{2, t}\right) .
$$

It follows that SMCE exists only if $1+\alpha<\beta_{2} f_{2}^{\prime}\left(\bar{L}_{2}\right) / f_{1}^{\prime}(\bar{L})$. Since $w_{t} / p_{t}<$ $f_{2}^{\prime}\left(\bar{L}_{2}+L_{2, t}\right)$, we must also have $1+\alpha>\beta_{2}$.

Proof of Proposition 2. We will first show that every SMCE, whenever exists, satisfies (19)-(27) and second that Eqs. (19)-(27) give us a SMCE if (17) and (18) hold.

Part 1. Every SMCE satisfies (19)-(27) for all t.

Let $\left\{w_{t}, p_{t}, L_{i, t}, q_{i, t}, c_{i, t}, M_{i, t+1} \mid i=1,2\right\}_{t=0}^{\infty}$ be SMCE. By Proposition 1, $w_{t} / p_{t}$ supports SMCE only if $w_{t} / p_{t}=\beta_{2} f_{2}^{\prime}\left(\bar{L}_{2}+L_{2, t}\right) /(1+\alpha)$. Besides, for type 2 agents cash-in-advance constraints are binding if $1+\alpha>\beta_{2}$, and not binding if $1+\alpha=\beta_{2}$. So, the labor market is always in equilibrium only if (19) and (20) hold. Equation (21) follows from (14) in Proposition 1. Regarding (24), $q_{1, t}$ derives from $q_{1, t}=\left(\sigma\left(1-\mu+\tau_{2}\right)+\mu+\tau_{1}\right) M_{t} /\left(N_{1} p_{t}\right)$, and $q_{2, t}$ from the good market clearing. Equation (25) restates (1) at the optimal plan. Finally, (26) and (27) follow from (15) and (16) in Proposition 1 along with the money market clearing and the stationarity of the money holding plans.

Part 2. The plan (19)-(27) is a SMCE if (17) and (18) hold.

We have to prove that the plan (19)-(27) is optimal and individually feasible, satisfies aggregate feasibility (market clearing) conditions and is stationary.

(2-i) Optimality

To check that both types optimize under the proposed prices and plans of action, we will make use of the Appendix Theorem in Basci and Saglam (2003). This theorem would for our problem propose that if the objective functions of type 1 and type 2 
agents are concave in their arguments, then the plans in (19)-(27) are optimal provided that these plans satisfy the Euler conditions and the transversality conditions. First note that $U_{1}\left(c_{1, t}\right)=U_{1}\left(f_{1}\left(\bar{L}_{1}+L_{1, t}\right)-w_{t} L_{1, t} / p_{t}+\left(M_{1, t}+\left(\tau_{1} / N_{1}\right) M_{t}-\right.\right.$ $\left.\left.M_{1, t+1}\right) / p_{t}\right)$ is jointly concave in $M_{1, t}$ and $M_{1, t+1}$ since $U_{1}$ is concave. For type 2 agents, $c_{2, t}=f_{2}\left(\bar{L}_{2}+L_{2, t}\right)-w_{t} L_{2, t} / p_{t}+\left(M_{2, t}+\left(\tau_{2} / N_{2}\right) M_{t}-M_{2, t+1}\right) / p_{t}$ if $1+\alpha=\beta_{2}$. In that case, $U_{2}\left(c_{2, t}\right)$ is jointly concave in $M_{2, t}$ and $M_{2, t+1}$ since $U_{2}$ is concave. If $1+\alpha>\beta_{2}, c_{2, t}=f_{2}\left(\bar{L}_{2}+\left(M_{2, t}+\left(\tau_{2} / N_{2}\right) M_{t}\right) / w_{t}\right)-M_{2, t+1} / p_{t}$. In that case, the desired concavity of $U_{2}\left(c_{2, t}\right)$ in $M_{2, t}$ and $M_{2, t+1}$ is still obtained as both $U_{2}$ and $f_{2}$ are concave. The plan (19)-(27) obviously satisfies the Euler conditions

$$
\begin{aligned}
U_{1}^{\prime}\left(c_{1, t}\right) & \geq \frac{\beta_{1} p_{t}}{p_{t+1}} U_{1}^{\prime}\left(c_{1, t+1}\right) \\
U_{2}^{\prime}\left(c_{2, t}\right) & =\frac{\beta_{2} p_{t}}{w_{t+1}} f_{2}^{\prime}\left(\bar{L}_{2}+L_{2, t+1}\right) U_{2}^{\prime}\left(c_{2, t+1}\right)
\end{aligned}
$$

for all $t$. The transversality conditions are also satisfied by the plan (19)-(27), since $\lim _{t \rightarrow \infty} \beta_{i}^{t}\left(-\frac{1}{p_{t}}\right) U_{i}^{\prime}\left(c_{i, t}\right) M_{i, t+1}=\lim _{t \rightarrow \infty} \beta_{i}^{t}\left(-\frac{1}{p_{0}}\right) U_{i}^{\prime}\left(c_{i, 0}\right) M_{i, 1}=0$ for all $i=1,2$.

(2-ii) Individual feasibility

In equilibrium, condition (8) of $\left(P_{1}^{\prime}\right)$ holds since

$$
-\bar{L}_{1} \leq L_{1, t} \leq \frac{M_{1, t}}{w_{t}}=-\frac{\mu L_{1, t}}{\sigma\left(1-\mu+\tau_{2}\right)} .
$$

At SMCE, condition (9) of $\left(P_{1}^{\prime}\right)$ becomes

$$
\mu(1+\alpha) \frac{M_{t}}{N_{1}} \leq(1+\alpha) \frac{M_{t}}{N_{1}}-(1-\sigma)\left(1-\mu+\tau_{2}\right) \frac{M_{t}}{N_{1}}+p_{t} f_{1}\left(\bar{L}_{1}+L_{1, t}\right),
$$

which holds if $(1-\sigma)\left(1-\mu+\tau_{2}\right) \leq(1+\alpha)(1-\mu)$. Condition (10) of $\left(P_{1}^{\prime}\right)$ is obviously satisfied by the plan (26). Condition (11) of $\left(P_{1}^{\prime}\right)$

$$
M_{1, t+1}-w_{t+1} L_{1, t+1}+\tau_{1}\left(M_{t+1} / N_{1}\right)=\left[\mu+\sigma\left(1-\mu+\tau_{2}\right)+\tau_{1}\right] \frac{M_{t+1}}{N_{1}} \geq 0
$$

holds only if $(1-\sigma)\left(1-\mu+\tau_{2}\right) \leq(1+\alpha)$, which is the case if $(1-\sigma)\left(1-\mu+\tau_{2}\right) \leq$ $(1+\alpha)(1-\mu)$. Condition (8) of $\left(P_{2}^{\prime}\right)$ holds as

$$
-\bar{L}_{2} \leq L_{2, t} \leq \frac{M_{2, t}+\left(\tau_{2} / N_{2}\right) M_{t}}{w_{t}}=\left(1-\mu+\tau_{2}\right) \frac{L_{2, t}}{\sigma\left(1-\mu+\tau_{2}\right)}=\frac{L_{2, t}}{\sigma} .
$$

If $\sigma\left(1-\mu+\tau_{2}\right)>(1+\alpha)(1-\mu)$, then condition (9) of $\left(P_{2}^{\prime}\right)$ is also satisfied by the SMCE plan since

$$
\begin{aligned}
M_{2, t+1} & <\frac{\sigma\left(1-\mu+\tau_{2}\right)}{(1+\alpha)(1-\mu)} M_{2, t+1}=p_{t} \frac{\beta_{2}}{1+\alpha} f_{2}^{\prime}\left(\bar{L}_{2}+L_{2, t}\right) L_{2, t} \\
& <p_{t} f_{2}\left(\bar{L}_{2}+L_{2, t}\right) .
\end{aligned}
$$


In equilibrium, condition (10) of $\left(P_{2}^{\prime}\right)$

$$
M_{2, t+1}+\tau_{2} \frac{M_{t+1}}{N_{2}}=\left(1-\mu+\tau_{2}\right) \frac{M_{t+1}}{N_{2}} \geq 0
$$

holds if $\sigma\left(1-\mu+\tau_{2}\right)>(1+\alpha)(1-\mu)$. (The condition $\sigma\left(1-\mu+\tau_{2}\right)=(1+\alpha)(1-\mu)$ is not consistent with the labor market clearing when $\mu=1$.) The SMCE plan also satisfies condition (11) of $\left(P_{2}^{\prime}\right)$ since

$$
M_{2, t+1}-w_{t+1} L_{2, t+1}+\left(\tau_{2} / N_{2}\right) M_{t+1}=\left(\sigma^{-1}-1\right) w_{t+1} L_{2, t+1} \geq 0 .
$$

Finally, there exists $\tau_{2} \in \mathbb{R}$ satisfying

$$
\frac{1-\sigma}{1+\alpha}\left(1-\mu+\tau_{2}\right) \leq 1-\mu<\frac{\sigma}{1+\alpha}\left(1-\mu+\tau_{2}\right)
$$

only if $\sigma>1 / 2$ holds.

\section{(2-iii) Aggregate feasibility}

Equations (22) and (23) are consistent with the labor market clearing. The plans in (24) clear the good market, and the plans (26) and (27) clear the money market.

\section{(2-iv) Stationarity}

One can easily verify that the plan (19)-(27) is stationary.

Proof of Proposition 3. Differentiating (29) with respect to $\alpha$ gives

$$
\begin{aligned}
\frac{d}{d \alpha}\left(w_{t} / p_{t}\right) & =-\frac{\beta_{2} f_{2}^{\prime}\left(\bar{L}_{2}+L_{2, t}\right)}{(1+\alpha)^{2}}+\frac{\beta_{2} f_{2}^{\prime \prime}\left(\bar{L}_{2}+L_{2, t}\right)}{1+\alpha} \frac{d}{d \alpha} L_{2, t} \\
& =-\frac{N_{2}}{N_{1}} f_{1}^{\prime \prime}\left(\bar{L}_{1}-N_{2} L_{2, t} / N_{1}\right) \frac{d}{d \alpha} L_{2, t} .
\end{aligned}
$$

So, $d L_{2, t} / d \alpha<0$ and $d\left(w_{t} / p_{t}\right) / d \alpha<0$. Differentiating (28) with respect to $\alpha$ yields

$$
\begin{aligned}
\frac{d Q_{t}}{d \alpha} & =N_{2}\left[f_{2}^{\prime}\left(\bar{L}_{2}+L_{2, t}\right)-f_{1}^{\prime}\left(\bar{L}_{1}-N_{2} L_{2, t} / N_{1}\right)\right] \frac{d L_{2, t}}{d \alpha} \\
& =N_{2} f_{2}^{\prime}\left(\bar{L}_{2}+L_{2, t}\right)\left(1-\frac{\beta_{2}}{1+\alpha}\right) \frac{d L_{2, t}}{d \alpha} .
\end{aligned}
$$

First note that $d Q_{t} / d \alpha<0$ if $1+\alpha \in\left[\max \left\{\beta_{1}, \beta_{2}\right\}, \beta_{2} f_{2}^{\prime}\left(\bar{L}_{2}\right) / f_{1}^{\prime}\left(\bar{L}_{1}\right)\right]$. Moreover, at $1+\alpha=\max \left\{\beta_{1}, \beta_{2}\right\}, d Q_{t} / d \alpha<0$ if $\beta_{1}>\beta_{2}$ and $d Q_{t} / d \alpha=0$, otherwise.

Proof of Proposition 5. The SMCE plan solves problems of all agents under the SMCE prices and clears all markets. Thus, (32) is clearly satisfied. Condition (31) holds only if $1+\alpha=\beta_{2}$. But, $1+\alpha=\beta_{2}$ supports SMCE only if $\beta_{1} \leq \beta_{2}$. Condition (33) and (34) hold if $q_{i, t}$ in (24) equals $-\left(w_{t} / p_{t}\right) L_{i, t}$. This is the case if $1-\mu+\tau_{2}=1+\alpha=\beta_{2}$. 


\section{References}

Barth, M.J., Ramey V.A. (2002) The cost channel of monetary transmission. In: Bernanke, B.S., Rogoff, K. (eds.) NBER Macroeconomics Annual 2001. The MIT Press, Cambridge, pp. 199-239

Başçı, E., Saglam, I. (1999) Does money matter? A deterministic model with cash in advance constraints in factor markets. In: Alkan, A., Aliprantis, C.D., Yannelis, N.C. (eds.) Current Trends in Economics: Theory and Applications. Springer, Berlin Heidelberg New York, pp. 107-118

Başçı, E., Saglam, I. (2003) On the importance of sequencing of markets in monetary economies. In: Koray, S., Sertel, M. (eds.) Advances in Economic Design, vol. 4. Springer, Berlin Heidelberg New York, pp. 297-316

Bewley, T. (1980) The optimum quantity of money. In: Kareken, J.H., Wallace, N. (eds.) Models of Monetary Economies. Federal Reserve Bank of Minneapolis, pp. 169-210

Christiano, L.J., Eichenbaum M., Evans C.L. (1997) Sticky price and limited participation models: A comparison. European Economic Review 41: 1201-1249

Christiano, L.J., Eichenbaum M., Evans C.L. (1998) Modeling money. NBER Working Paper 6371

Cooley, T.F., Hansen G.D. (1989) The inflation tax in a real business cycle model. American Economic Review 79: 733-748

Friedman, M. (1969) The Optimum Quantity of Money and Other Essays. Aldine, Chicago

Fuerst, T.S. (1992) Liquidity, loanable funds and real activity. Journal of Monetary Economics 29: 3-24

Grandmont, J.M., Younes Y. (1973) On the efficiency of a monetary equilibrium. Review of Economic Studies 40: 149-165

Grossman, S., Weiss, L. (1983) A transactions-based model of the monetary transmission mechanism. American Economic Review 73: 871-880

Kormendi, R., Meguire, P. (1985) Macroeconomic determinants of growth: Cross-country evidence. Journal of Monetary Economics 16: 141-163

Levine, R., Renelt, D. (1992) A sensitivity analysis of cross-country growth regressions. American Economic Review 82: 942-963

Lucas, R.E.J., Stokey, N.L. (1987) Money and interest in a cash-in-advance economy. Econometrica 55: 491-513

Rotemberg, J.J. (1984) A monetary equilibrium model with transaction costs. Journal of Political Economy $92: 40-58$

Stockman, A.C. (1981) Anticipated inflation and the capital stock in a cash-in-advance economy. Journal of Monetary Economics 8: 387-393

Woodford, M. (1990) The optimum quantity of money. In: Friedman, B.M., Hahn, F.H. (eds.) Handbook of Monetary Economics. North-Holland, Amsterdam, pp. 1067-1152

Woodford, M. (1994) Monetary policy and price level determinacy in a cash-in-advance economy. Economic Theory 4: 345-380 